\title{
Risk Assessment for Illegal Waste Open Burning
}

\author{
Gianpiero Buzzo ${ }^{1^{*}}$, Gabriella Gigante ${ }^{1^{*}}$, Francesco Nebula $^{1^{*}}$, Roberto Palumbo ${ }^{1^{*}}$, Domenico Pascarella ${ }^{*}$, Angela Vozella $^{{ }^{*}}$ \\ ${ }^{1}$ CIRA ScPA, Safety and Security Department, 81043 via Maiorise 1, Capua - CE - Italy
}

\begin{abstract}
The area of Naples and Campania region, in Italy, has been experiencing the dramatic consequences of diffuse open burning of illegal waste, resulting in possible threats to human health. The need of evaluating a risk index of open burning rises from this emergency where it is important quantify the risk to support local stakeholder to intervene timely and effectively order and to prioritize the interventions. Nevertheless, open burning phenomenon is still uncontrolled all over the world, and implies not only impacts on health at local level but emission of pollutants in the atmosphere. A deep understanding can support policy makers in order to prevent risky behaviours and to mitigate the severity of their occurrences. The risk model related to open burning is still an open issue, and the attempt to model the probability of its occurrence is completely new. This paper proposes a model for the evaluation of risk of illegal waste open burning in Campania enabling the identification of the priority of intervention in order to optimize the available resources. In detail, it defines a layered and seamless approach to evaluate the related impact at different levels of accuracy leveraging on reference guidelines.
\end{abstract}

\section{Introduction}

Risks related to emissions of air contaminants are relevant for human health, those from open burnings currently are still uncontrolled. The term Open burning refers to the incineration of discarded products typically at low temperatures and in an uncontrolled manner, in order to reduce the quantity of waste. Open burning of waste releases a variety of toxic pollutants into the air and can also imply soil pollution, water pollution and food contamination. The World Bank considers it as an uncontrolled Global Health disaster, estimating that the $41 \%$ of global waste is burned openly, even higher in poor or emergent countries, as reported in Fig. 1, obtained from [1]. It releases significant amounts of greenhouse gases into the atmosphere. Such compounds include carbon dioxide, methane and particulate matter, which are typically associated with air pollution and can lead to severe cases of respiratory disease.

\begin{tabular}{|l|l|l|l|}
\hline Pollutant & $\begin{array}{l}\text { Global Emission } \\
\text { due to open } \\
\text { burning } \\
\text { (kg/year) }\end{array}$ & $\begin{array}{l}\text { \% of total } \\
\text { global } \\
\text { emissions of } \\
\text { pollutant }\end{array}$ & $\begin{array}{l}\text { Potential health } \\
\text { impacts }\end{array}$ \\
\hline $\begin{array}{l}\text { Coarse Particulates } \\
\left(\mathrm{PM}_{10}\right)\end{array}$ & 12 Billion & 24 & $\begin{array}{l}\text { - } \\
\text { - } \begin{array}{l}\text { Lung cancer } \\
\text { Respiratory } \\
\text { disease }\end{array}\end{array}$ \\
\cline { 1 - 2 } $\begin{array}{l}\text { Fine Particulates } \\
\left(\mathrm{PM}_{2,5}\right)\end{array}$ & 10 Billion & 29 & Heart failure \\
\cline { 1 - 2 } Black Carbon (BC) & 632 Million & 11 & \\
\hline Organic Carbon (OC) & 5.1 Billion & 43 & \\
\hline
\end{tabular}

Fig. 1. Estimations of global pollutants emitted by open burning [1].

Though in many countries the open burnings are forbidden and considered a crime, the phenomenon is very spread since it represents a fast, effective and inexpensive way to reduce waste. Countries with a poor collection coverage or, on the contrary, with expensive services, exhibit a great percentage of waste reduced by means of open burning. The area of Naples and Campania region, in Italy, has been experiencing in the last decade the dramatic effects of diffuse open burning, resulting in serious consequences on human health and damages to the ecosystem, complex to repair.

Recent studies evaluate the economic benefit of reducing negative outcomes resulting in general from illegal waste management. The evaluation of the risk implied by the burning of the illegal landfill is a key element to design effective and efficient countermeasure policies, enabling the identification of the priorities of intervention. The assessment of the risk implied by open burning is still an open issue and the attempt to model the probability of its occurrence is completely new. The evaluation of the probability of burning addresses sociocultural elements (lack of solid waste management policies and infrastructures, inertia to change the habits), whereas the evaluation of the related impact relies on guidelines and on references to a very specific literature that sometimes can result fragmentary, analysing different relevant aspects: from the emission of contaminants, in terms of types and concentration, to the typical composition of an illegal waste according to the different seasons. Existing tools to evaluate the risk apply mainly to plants. A unique approach for the evaluation is still missing. This paper proposes a model for the evaluation of risk of illegal waste open burning in Campania. Such a model, integrated in an appropriate decision support system, enables the definition of the priority of intervention in order to optimize the available resources.

\footnotetext{
* Corresponding author: g.buzzo@cira.it
} 
Intervention aims to mitigate the related risk removing the illegal waste and the resources needed form economic to human effort, need to be properly used. The priority can be determined on the basis of the risk and the available resources. In detail, it defines a layered approach to evaluate the related impact at different levels of accuracy and of available data, leveraging on reference guidelines and literature in order to evaluate toxicity and exposure factors in a seamless framework. It provides some preliminary considerations on the evaluation of the probability in terms of identified influence factors. Considerations on the validation of the overall model are reported.

The paper is structured as follows. In Section 2, it reports the Related work of the research problem addressing some key elements, the guidelines, the state-ofthe-art for contaminant transport models in air. Section 3 details the defined approach for the evaluation of the impact of an open burning, providing considerations on the possible approaches to the modelling of the probability of occurrence and some preliminary considerations on the validation of the model. Section 4 reports the conclusion.

\section{Related work}

Experience and culture in the field of environmental and health risk assessments are widely consolidated in case of contaminated sites. However, the situation is very different when referring to the landfill sector, where the knowledge and experience are very low, even more in the case of open burning. Literature lacks integrated approaches to the evaluation of risk related to open burning. For example, there are guidelines to evaluate the impact in terms of toxicity and the exposure, but they leave the quantification of the initial concentration of contaminants to the single research initiative, implying different approaches not allowing a sound comparison among the different obtained risk indexes. In the following, we briefly analyse the stateof-the-art of some pillars of the proposed approach: the guidelines, the average compositions of illegal dumps, and the models for transport of contaminants in air.

\subsection{Environmental risk assessment}

Risk assessment as a formal discipline emerged in the 1940s and 1950s, paralleling the rise of the nuclear industry as well as in aerospace. Risk assessment considers the likelihood of occurrence and the consequences of the occurrence of an event. It represents a systematic means of determining and evaluating the nature, effect and extent of exposure that a vulnerable receptor may experience in relation to a particular hazard. There are, of course, several varieties of risk assessment. Environmental Risk Assessment (ERA) include Human Health-Risk Assessments (HHRAs) and Ecological Assessment. HHRA had its beginnings in 1976 with the US Environmental Protection Agency (US EPA) publication of the Carcinogenic Risk Assessment Guidelines. In this paper, we are concerned with the first one being the identified hazard the contaminants of the air, produced by the open burning of an illegal dump waste. The Exposure Assessment determines the concentration of the contaminating agent in the environment and estimates its rate of intake in target organisms. The US EPA's Information Centre at Research Triangle Park, have been providing several databases with publications since 1987. EPA has performed the researches since the middle of 1990s, estimating the emission factor and emission volume from the waste open burning. Most researches have focused on the analysis of air pollutants such as dioxins, carcinogenic elements, carbon monoxide and particulate matters. , A good summary of all relevant references and studies on emission factors is provided in [2] and reported in Fig. $2[3,4]$

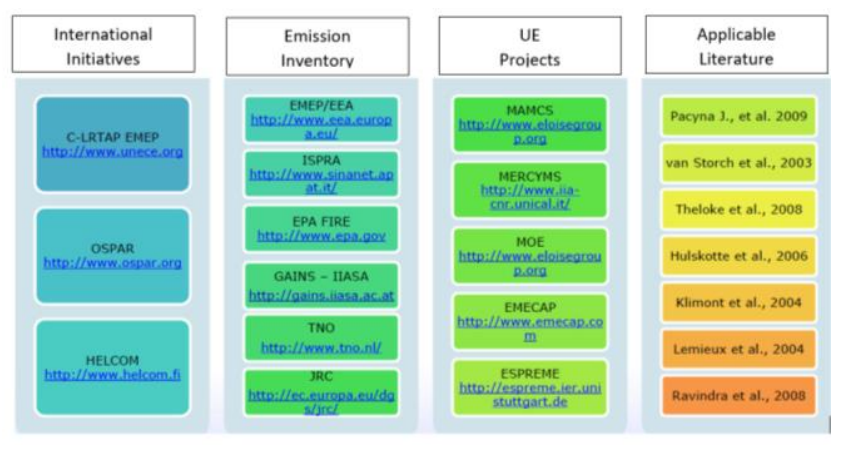

Fig. 2. Summary of related work on emission factors.

The key point for our work is to map the possible materials burned and the studies on related emission, in order to build a model as more comprehensive as possible. There are still several emission factors data we did not find such as: combustion of animal carcasses, accidental fires, construction debris, and grain silo fires. However, the percentage of their presence in open dumping is currently low.

\subsection{Physical composition and density of illegal dump}

Physical composition is the term used to describe the individual components that make up solid waste stream and their relative distribution, usually based on percentage by weight. The elemental composition of waste helps in predicting the gaseous emissions. Usually, the mode of physical composition of illegal open dumps is about the $90 \%$ municipal solid waste (MSW). MSW varies throughout the world. Even in the same country it changes from place to another as it depends mainly on two factors: (1) income level of the country; and (2) extent of industrialization. Income level affects the main. An interesting work [3] reports the average percentage of physical compositions in the high-, middle- and low-income countries, Fig. 3. 


\begin{tabular}{cccc}
\hline \hline Component & $\begin{array}{c}\text { High } \\
\text { Income }\end{array}$ & $\begin{array}{c}\text { Middle } \\
\text { Income }\end{array}$ & $\begin{array}{c}\text { Low } \\
\text { Income }\end{array}$ \\
\hline $\begin{array}{c}\text { Food wastes } \\
\text { Paper }\end{array}$ & $\begin{array}{c}7 \text { to } 55 \\
15 \text { to } 50\end{array}$ & $\begin{array}{c}20 \text { to } 65 \\
15 \text { to } 40\end{array}$ & $\begin{array}{c}40 \text { to } 85 \\
1 \text { to } 10\end{array}$ \\
$\begin{array}{c}\text { \&ardboard } \\
\text { Plastics }\end{array}$ & 2 to 20 & 2 to 13 & 1 to 11 \\
Leather & 2 to 12 & 1 to 5 & 1 to 3 \\
\&Rubber & & & \\
Glass & 4 to 10 & 1 to 10 & 1 to 10 \\
Metal & 3 to 13 & 1 to 5 & 1 to 5 \\
Ash \&Dirt & 5 to 20 & 15 to 40 & 15 to 50 \\
Textiles, & & & \\
Moisture $(\%)$ & 20 to 35 & 40 to 60 & 40 to 80 \\
Density $\left(k g / m^{3}\right)$ & 120 to & 170 to & 250 to \\
& 200 & 330 & 500
\end{tabular}

Fig. 3. Waste composition of high-, middle-, and low-income countries [3].

The EPA estimated the amount of MSW generation in the United States with 254 million tons in 2013 [5]. The composition and classification by material is given in Fig. 4.

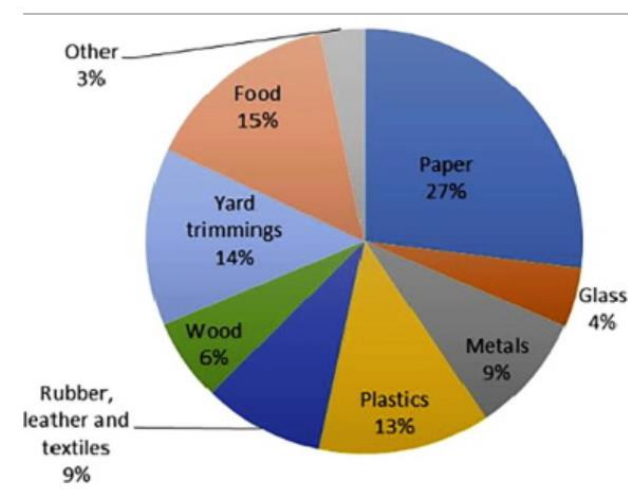

Fig. 4. Composition and classification (by material) of MSW generated by the United States in 2013 [5].

Density is another important characteristic of solid waste which, jointly with the total volume, is essential to estimate the total mass of waste that can be burned. Density can highly depend on the season of the year. Reference [4] provides an estimation of densities of different elements and also during different seasons.

\subsection{Air transport modelling}

The quantification of the potential exposure levels of the contaminants at the receptor location is allowed by the evaluation of its concentration in each exposition point (Point of Impact) under study. Air quality modelling is an important tool to quantify the impacts of emission sources on ambient air quality. It correlates the emissions to atmospheric concentrations and deposition by means of meteorology, orography and other influence factors. The understanding of the diffusion properties of plumes emitted from large industrial stacks has paved the way to a flourishing literature, leading to the development of many Air Quality Models (AQMs) to evaluate the impacts of industrial air pollution. Numerical modelling can be divided into two main classes: Lagrangian and Eulerian modelling. In Lagrangian modelling, an air parcel (or "puff") is followed along a trajectory, and is assumed to keep its identity during its path. In Eulerian modelling, the area under investigation is divided into grid cells, both in vertical and horizontal directions. Since 1980, the basic modelling concepts and tools have been available to the scientific community. The most used models are AERMOD and CALPUF [6]. AERMOD is today replacing the Industrial Source Complex (ISC) models for most regulatory applications in the US. CALPUFF is particularly recommended for long-range simulations (e.g., more than 50 miles). In spite of the consolidation of the usage of some models, the most relevant issue of the models is represented by the meteorological factors, since they can affect the accuracy of the model; the more accurate they are, the more accurate the concentration can be evaluated. Moreover, recent studies focus their attention on photochemical models [7]. They simulate the changes of pollutant concentrations in the atmosphere using a set of mathematical equations characterizing the chemical and physical processes in the atmosphere. These models are applied at multiple spatial scales from local, regional, national, and global.

\section{Risk assessment model}

\subsection{The context}

Campania aims to build an information management system for the open dumping and burning tracking and analysis. The risk related to the open burning on an illegal dumpsite has to be assigned to each identified site along three possible case studies: 1) a-priori when assigned to areas that historically are prone to illegal dumping and burning, 2) once the illegal landfill has been detected, 3) during the occurrence of the open burning. The risk index $R_{\text {site }}$ relating to the fire of the generic open dumping site is given by:

$$
R_{\text {site }}=P \times I,
$$

where $P$ is the probability of burning occurrence and $I$ represents the impact that the fire causes on man in a certain Region of Interest (RoI), The impact $I$ is evaluated as the sum of the impacts on each environmental matrix (soil, air, water), i.e.:

$$
I=I_{\text {soil }}+I_{\text {air }}+I_{\text {water }}
$$

In this work, we concentrate on the air matrix. It is given by;

$$
\begin{aligned}
I_{\mathrm{air}} & =\sum_{j} I_{j} \\
H Q_{\mathrm{air}} & =\sum_{j} H Q_{j}
\end{aligned}
$$


being $I_{j}$ the Impact for and non-carcinogenic emissions the Hazard Quotient (HQ) for non-carcinogenic emissions for the contaminant $j$. Such impact is quantified as:

$$
I_{j} \text { or } H Q_{j}=F_{P_{j}} \times F_{E_{j}}
$$

being $F_{P_{j}}$ the quantification of the toxicity and the danger that the contaminant may imply, and $F_{E_{j}}$ the daily chronic intake of the contaminant.

Guidelines determine the following tolerance level within the risk index. For carcinogenic emissions, the target risk $(\mathrm{TR})=10^{-6}$ in the case of a single pollutant and TR $=10^{-5}$ in the case of cumulative value for multiple pollutants. In our work, the adopted scale of risk thresholds is reported in Table 1.

Table 1. Scale of risk thresholds

\begin{tabular}{|l|l|l|}
\hline 4 & Very Serious & Iair $^{-=10^{-5}}$ \\
\hline 3 & Serious & $\mathbf{1 0}^{-6} \mathrm{I}_{\text {air }}<10^{-5}$ or $\mathrm{HQ}_{\text {air }}>0,9$ \\
\hline $\mathbf{2}$ & Medium & $\mathbf{1 0}^{-7}<=\mathrm{I}_{\text {air }}<\mathbf{1 0}^{-6}$ or $0,5<=\mathrm{HQ}_{\text {air }}<0,8$ \\
\hline 1 & Slight & $\mathrm{I}_{\text {air }}<\mathbf{1 0}^{-7}$ and $0<\mathrm{HQ}_{\text {air }}<0,5$ \\
\hline
\end{tabular}

\subsection{Conceptual model}

The risk assessment techniques are based on a causal model of stress response in which a contaminant is transported from a source through a known path to a receptor (people, plants, animals). In this work: the source is represented by the contaminant substances emitted by means of illegal waste open burning the pathway is represented by the air transport of contaminant; the receptor is represented by the people in an area surrounding the illegal waste. The conceptual model has been defined according to a layered approach in order to always assure a quantitative evaluation, also in case of lack of data.

The model is designed according to four different layers leveraging on varies assumptions or data availability in the system. Of course, the layers address different level of accuracy (from layer 1, the less accurate, to level 4, the most accurate).

\subsection{Source characterization}

The micro-landfill must be characterized by geographic coordinates; the area that it covers, by the height and by the material that composes it. For the calculation of the risk, the following dimensions of the micro-landfill are considered as the base area, the area of the rectangle determined by the maximum extensions in the plane in width and length as height the maximum height that can be found. If the dimensions are not found in the input data, a volume equal to $V=A \times H=15 \mathrm{~m}^{2} \times 1.5 \mathrm{~m}=$ $22.5 \mathrm{~m}^{3}$ will be considered. Similarly, if the composition is not detectable by satellite, the micro-landfill can be considered: similar to domestic solid waste (newspapers, paper packages, compostable, other bio fuel, sum of bio fuel, hard plastic, soft plastic, diapers, other fossil fuels, sum fossil fuel, glass packages, metal packages, other non combustion); or as an aggregate of specific substances according to a division in parametric percentage between plastics, tires, fabrics, paper, agricultural materials, oils. According to the available data, the characterization of the primary and secondary sources will follow the layered approach previously introduced.

Characterization of the Primary Source

Lev. 1

a) Determination of geometry based on default parameters derived from historical data

b) Determination of the composition evaluated on the basis of statistical data and for which the emission values of polluting substances in burning houses are known

Lev. 2

a) Determination of geometry on the basis of parameters generated according to a random distribution

b) Composition generated according to a random distribution and for which the emission values of polluting substances in burning houses are known

Lev. 3

a) Geometry determination based on satellite image analysis

b) Determination of the composition based on analysis of satellite images

Lev. 4

a) Geometry determination on the basis of in situ measurement

b) Determination of the Composition on the basis of in situ measurements

\section{Characterization of the Secondary Source}

Lev. 1

a) Issued substances identified with respect to the composition evaluated

b) Average density assessment based on literature data

c) Determination of emission factors on the basis of data from literature

Lev. 2

a) Issued substances identified with respect to the composition evaluated

b) Assessment on the average density based on literature data

c) Determination of emission factors on the basis of literature data

Lev. 3

a) Issued substances identified with respect to the composition evaluated

b) Evaluation of the average density based on literature data

c) Determination of emission factors based on literature data

Lev. 4

a) Emitted substances evaluated during the open burning event

\subsubsection{Pathway characterization}


The routes and methods of exposure are those by which the potential target comes into contact with the contaminating chemical species. In this work, we focus on the ways of exposure outdoor air (OA), indoor air (IA). Air transport is simulated through atmospheric transport models and is determined by a set of other elements: the extent of the region of interest, the territorial context, the weather conditions. The first defining the spatial scale of the model to be built, is determined by the available transport models, and can range from $10 \mathrm{~km}$ from the emission point to $50 \mathrm{~km}$. The territorial context instead considers the orography of the affected area. It can be, for example, flat territory or complex territory. The weather conditions address the vertical profile of the wind and other parameters such as rain, humidity, pressure.

For this work it is assumed:1) the region of interests as a default volume of $15 \mathrm{~km} * 15 \mathrm{~km}$ for a height of $10 \mathrm{~m} ; 2$ ) the territorial scope is flat territory; 3 ) the concentration of the individual pollutant: $a$. it is equal to the initial one in all the cells of the RoI (in the most conservative case of default); 4) as a parametric attenuation factor expressed as a percentage of the initial concentration on a certain number of cells in the 4 directions $\mathrm{N}, \mathrm{S}, \mathrm{E}, \mathrm{W}$.

The choice of the "local" spatial scale is made on the basis of an average value that the different air transport models can ensure. Some models even calculate the concentrations of substances up to a radius of $200 \mathrm{~km}$. However, given the high concentration of micro-landfills in particular areas of Campania, the assessment within this range is still considered reasonable. The territorial area then considers the territory flat ensuring unimpeded transport in order to provide conservative estimates with the exception of particular cases, such as creations of singularities in valleys or on peaks. On the basis of layered approach adopted, the pathway characterization will be the following:

Lev. 1

a) Determination of the concentration of the pollutant in $j$ point by equation

b) Initial concentration based on evaluation of emission factors and average density

c) Transport factor determined by analytical models

d) Transport factor determined as linear abatement in different directions

e) Territorial area: flat (no orography)

Lev. 2

a) Determination of the concentration of the pollutant in $x$ point by equation

b) Initial concentration based on evaluation of emission factors and average density

c) Transport factor determined by analytical models

d) Territorial area: flat (no orography)

Lev. 3

a) Determination of the concentration of the pollutant in $x$ point by equation

b) Initial concentration based on the assessment of emission factors and average density

c) Transport factor determined by analytical models

d) Territorial area: flat (no orography)

Lev. 4

a) Determination of the concentration of the pollutant in $x, y$ point of the RoI by means of simulation based on numerical models (Use of weather and orography data)

\subsubsection{Receptor characterization}

As for the targets of contamination, this work considers only human receptors for the purpose of carrying out a health risk analysis. These receptors can be both adults and children and differ according to: - their location: for this purpose, on-site targets are defined as those located at a maximum of $500 \mathrm{~m}$ from the source of contamination, and off-site targets are those that are from $500 \mathrm{~m}$ away from the source of contamination to the upper limit of the region concerned the intended use of the land. Three types of land use have been considered: Residential (presence of houses that are habituated), Recreational (any area in which people spend a limited period of free time), Industrial/Commercial (areas where the people exposed to the greatest contamination risk are the workers present on the site).

For this work it is assumed: 1) the targets are square cells of $500 \mathrm{~m} * 500 \mathrm{~m} * 10 \mathrm{~m}$ in height within the identified ROI; 2) the Time Scale is short term (for example, hours or days, i.e. linked to the single fire event) and does not consider cumulative effects.

On the basis of layered approach, the receptor characterization will be as follow:

Lev. 1

a) Risk assessment according to types of residential and industrial use

b) Determination of dimensions and geometry according to default values

Lev 2.

a) Evaluation on the basis of historical data of the type of use of the environment

b) Determination of dimensions and geometry according to a random distribution

Lev. 3

a) Evaluation on the basis of historical data of the type of use of the environment

b) Determination of the size and geometry of the Region of Interest with respect to historical weather conditions

Lev. 4

a) In situ assessment of the type of use of the environment

b) Determination of the size and geometry of the Region of Interest with respect to historical weather conditions

\subsection{Impact evaluation}

As said before, Impact is the product of Toxicity factor $\left(F_{P}\right)$ for the Exposure factor $\left(F_{E}\right)$, as shown in equation (4). The toxicity factor is driven by reference guidelines, an example is reported in Table 2 [3].

Table 2. Example values of Slope Factor (SF)and Reference Dose $\left(\mathrm{R}_{\mathrm{f}} \mathrm{D}\right)$ for dioxin and $\mathrm{NO}_{3}$ 


\begin{tabular}{|c|c|c|}
\hline Contaminant & $\begin{array}{c}\text { Oral Chronic } \\
\text { Reference Dose } \\
\text { (mg/kg-day) }\end{array}$ & $\begin{array}{c}\text { Oral Slope Factor } \\
\text { (mg/kg-day) }\end{array}$ \\
\hline TCDD, 2,3,7,8- & $7 \mathrm{E}-5$ & 0,000038 \\
\hline $\mathrm{NO}_{3}$ & 1.6 & \\
\hline
\end{tabular}

The $\mathrm{F}_{\mathrm{Ek}, \mathrm{j}}$ factor for each $k$-cell of the considered region of impact, represents the chronic daily intake of the contaminant $j$ and is given by the product between the concentration, calculated at the exposure point $E_{k, j}$, and the actual flow rate of exposure EM, which can represent the amount of air inhaled per day per unit of body weight:

$$
\begin{gathered}
F_{j}^{E}=E_{k, j} \cdot E M \\
E_{k j}=E_{0 j} \cdot F T_{k, j}
\end{gathered}
$$

where $E_{0 j}$ represents the concentration of the $j$-th contamination substance at the open burning site and $\mathrm{FT}_{\mathrm{j}}$ is the transport factor of the pollutant $\mathrm{j}$-th in the atmosphere. Due to the multiplicity and variety of materials that can burn (paper, plastic, food, clothing, metals, etc.) it is very difficult to make a precise estimate of the specific concentration. For these reasons, US EPA defines a possible approach to the estimation of emission relating the quantity of a pollutant released to the atmosphere with an activity associated with the release of that pollutant:

$$
E_{0 j}=A \cdot E F_{j} \cdot(1-E R / 100)
$$

Where: $\mathrm{E}=$ emission at the burning site; $\mathrm{A}=$ activity factor; $\mathrm{EF}_{\mathrm{j}}=$ emission factor concerning the $\mathrm{j}$ pollutant; ER is the overall efficiency of any emissions abatement system.

The activity factor depends on the kind of the phenomenon of interest. It can be the activity of an engine, of an industrial chimney. The activity factor is defined in terms of the mass combusted per unit time or per unit area within the region or facility of interest. As reported in [8] US EPA assigns the EF emission factors a degree of reliability from $\mathrm{A}$ to $\mathrm{E}$ considering $\mathrm{A}$ the most reliable value. The reliability assigned to the emission factors related to open burning ranges from $\mathrm{C}$ to $\mathrm{D}$. For a correct assessment of the emission factor, the composition of the landfill must first be characterized. As part of present work, landfills have been divided into two classes: domestic waste and differentiated composition. In the first case, the composition of the landfill is assimilated to the typical mixed composition of solid domestic waste (newspapers, paper packages, compostable, plastic, diapers, glass packages, tires, oils and so on) and therefore addresses certain values found for the category in question. In the second case, the landfill is assimilated to a set of materials according to a certain percentage of composition and the emissive values of the individual burned materials are considered, which are then composed linearly according to

\begin{tabular}{|c|c|c|c|c|c|c|}
\hline Material & $\begin{array}{c}\text { PM } \\
(\mathrm{g} / \mathbf{M} \\
\mathrm{g})\end{array}$ & $\begin{array}{c}\text { Dioxi } \\
\text { n } \\
(\mathrm{mg} / \mathrm{k} \\
\mathrm{g})\end{array}$ & $\begin{array}{c}\text { PAH } \\
(\mathbf{m g} / \mathbf{k} \\
\text { g) }\end{array}$ & $\begin{array}{c}\text { NO } \\
\mathbf{x} \\
(\mathrm{g} / \mathrm{k} \\
\mathrm{g})\end{array}$ & $\begin{array}{l}\text { SOx } \\
(\mathrm{kg} / \\
\mathrm{Mg})\end{array}$ & $\mathrm{CO}$ \\
\hline $\begin{array}{l}\text { Domestic } \\
\text { waste }\end{array}$ & 8 & $\begin{array}{c}5,8 * 1 \\
0-3\end{array}$ & 11,36 & 3 & 0,5 & 42 \\
\hline \multicolumn{7}{|l|}{$\begin{array}{l}\text { Differenti } \\
\text { ated } \\
\text { compositi } \\
\text { on }\end{array}$} \\
\hline Plastic & & $\begin{array}{c}2,57 \\
* 10^{-4}\end{array}$ & 405 & & & \\
\hline Tires & 140,9 & $*$ & $\begin{array}{c}2917, \\
83\end{array}$ & & & \\
\hline Paper & 11 & & & 1,64 & 0,03 & 58 \\
\hline Oils & 0,22 & $\begin{array}{c}4,28^{*} \\
10^{-4} \\
\end{array}$ & 221 & 2,4 & 2,27 & 0,61 \\
\hline $\begin{array}{l}\text { Agricultu } \\
\text { ral } \\
\text { material } \\
\text { (Turf) }\end{array}$ & 0,008 & & & & & $\begin{array}{c}0,04 \\
2\end{array}$ \\
\hline
\end{tabular}
the hypothesized composition percentages. Table 3 lists the emission rate for some kind of contaminant.
In the hypothesis of our work, the activity factor depends on the mass that burns. If we suppose that it burns the whole mass of the landfill before there is dispersion, it is possible to assimilate the Activity factor to the mass of the landfill that is obtained starting from its volume and medium density. If the landfill is assimilated to generic solid waste:

$$
A \cong m=\rho_{\text {medium }} * V
$$

In case of parametric and differentiated composition:

$$
A \cong m=\sum m_{i}=\sum_{i} \rho_{i} \cdot\left(w_{i} * V\right)
$$

Where: $\mathrm{i}$ indicates the $\mathrm{i}$-th material which composes the landfill; $\rho_{i}$ is the density of the $\mathrm{i}$-th material; $\mathrm{w}_{\mathrm{i}}$ the weight as a percentage of each material making up the landfill; $\mathrm{V}$ is the total volume of the landfill. For domestic waste, the medium density is assumed equal to a value of literature evaluated in [4] according to Table 4.

Table 4. Average density of domestic waste according to the different seasons.

\begin{tabular}{|l|c|}
\hline Season & Density $\left[\mathbf{k g} / \mathbf{m}^{\mathbf{3}}\right]$ \\
\hline Autumn & 210 \\
\hline Winter & 200 \\
\hline Spring & 210 \\
\hline Summer & 250 \\
\hline
\end{tabular}

In the case of a structured composition of the landfill, the density is given by the weighted average of the densities of the individual components where the weight is the percentage chosen for the specific class of materials. The density values of the classes of material such as Plastic, Paper, Tires, Textiles, Oils are taken from the reference literature [9] according to Table 5.

Table 3. Emission factors of pollutants by type of material [9]. 
Table 5. Average density of kind of materials that make up the landfill.

\begin{tabular}{|l|c|}
\hline \multicolumn{1}{|c|}{ Material } & $\begin{array}{c}\text { Medium } \\
\text { Density } \\
\left(\mathbf{k g} / \mathbf{m}^{\mathbf{3}}\right)\end{array}$ \\
\hline Mixed plastic & 116 \\
\hline Paper (Mixed paper, card \& drink cartons) & 366 \\
\hline Tires & $840[4,10]$ \\
\hline Textiles & $237[5]$ \\
\hline Oils & $820\left(\right.$ at $\left.15^{\circ} \mathrm{C}\right)$ \\
\hline Turf & 338 \\
\hline
\end{tabular}

With regard the emission abatement system, for this work any system was taken into consideration, therefore it was assumed that the whole landfill mass burns completely.

There are three different ways to calculate FT: 1. By means of models of transport in the atmosphere, which provide the concentration factor on each cell considering the initial conditions, the weather and orographic conditions; 2 . by means of a simplified analytical model including considerations on some meteorological factors such as wind velocity, incident solar radiation, etc.; 3 . Defining a linear model for the transport. The proposed approach can be integrated with all these options.

The assessment of the effective $E M$ exposure flow translates into the estimate of the daily dose of the environmental matrix considered, which can be taken by the human receptors identified in the conceptual model. As part of our work, the inhalation of dust resulting from open burning waste was considered, in both outdoor and indoor environments for adult and child concurrently. The calculation of the $E M$ in the outdoor case is shown below

$$
\begin{gathered}
E M=\frac{B_{O A d} \cdot E F_{g} \cdot E F \cdot E D_{A d}}{B W_{A d} \cdot A T \cdot 365 \frac{\text { days }}{\text { year }}} \\
\frac{B_{\text {OChild }} \cdot E F_{g} \cdot E F \cdot E D_{\text {Child }}}{B W_{\text {Child }} \cdot A T \cdot 365 \frac{\text { days }}{\text { year }}},
\end{gathered}
$$

Where: $B_{0}$ is the outdoor inhalation factor; $E F$ is the frequency of exposure; $\mathrm{EF}_{\mathrm{g}}$ is the daily frequency of exposure; $\mathrm{ED}$ is the duration of the exposure; $\mathrm{BW}$ is the body weight during the exposure period; AT is the average time of exposure of an individual to a substance.

In this work, the default values for the exposure factors have been used, as reported in the Appendix I of [11].

\subsection{Case studies and application of the approach}

In all case studies, the impact is evaluated according to the same calculations but used data are different. To cover the first case study Campania region is discretized in $n$ hexagonal cells of about $60 \mathrm{~km}$ of side (named Regional cells) according to the requirements of Campania region stakeholder. An impact index has to be assigned to each regional cell. Nevertheless, the spatial extension of the regional cells can be too wide for the required spatial resolution of the impact index according to the applied dispersion model. For this reason, the impact evaluation is performed according to the following steps: 1) the regional cell is further divided in smaller cells (named basic cells) with the most proper spatial extension; 2) A possible open dump is positioned in the centroid of each basic cell; 3 ) the
Impact is evaluated for each basic cell; 4) The impact of the regional cell is assumed to be the maximum of the impact indexes of its basic cells. For each cell the overall risk is given by

$$
I_{\text {regional cell }}=\max \mathrm{I}_{i}
$$

where $\mathrm{i}=\mathrm{i}$-th basic cell. In the second and third case studies, the site of open dumping is provided as input and $\mathrm{R}$ is evaluated for each single site according to the formula defined in the previous section. In both case studies, concentration can be evaluated according to two different ways by means of the linear model or the analytical model, using historical data on wind velocity, incident solar radiation, cloud coverage. Such data are the average evaluated on the reference season for the elaboration. Meteorological data are provided by COSMO model [8] managed at CIRA premises and can provide a temporal resolution of 1 hour and spatial resolution of $1 \mathrm{~km}$. The resulting calculated risk index is assigned to each hexagonal cell and mapped in stakeholder's GIS application. The risk picture is built and can support the monitoring activities. In the third use case, the concentration can be evaluated by means of the analytical model, or using numerical model, punctual and current meteorological data elaborated always according to COSMO model.

\subsection{Preliminary considerations on validation of the model}

The impact model relies on the evaluation of toxicity and exposure. The exposure and the toxicity factors are driven by guidelines, instead the level of the toxicity depending on turn on the concentration of the pollutant in a fixed point is determined within the proposed approach and needs validation. Therefore, the validation strategy focuses on the evaluation of the pollutant concentration. In order to validate and also tune the model, we would need a set of data to be used as an oracle. Such data should provide the concentration of all pollutants foreseen by the model, according to the spatial and temporal accuracy of interest. Data related to open burning are very fragmentary, do not address all contaminants and are not uniform with respect to the spatial and temporal accuracy. This will require a pre-processing of data, applying a filter in order to obtain the desired accuracy. In addition to assure a sound comparison among the calculated and the measured data, some information (such as the measurement sensor, the time, and also data characterising the landfill) should be available too. A possible/first method to validate the model could perform a comparison between the calculated value and the measured one in terms of Point Percentage variation $(\mathrm{D}(\operatorname{var} \%))$.

$$
D(\operatorname{var} \%)=\frac{(\text { EvalConc }- \text { MeasConc })}{0,5 \cdot(\text { EvalConc }+ \text { MeasConc })},
$$

Where: EvalConc is the evaluated concentration by the proposed model; MeasConc is the measured concentration. 
To perform a complete validation, further information on available data have been required to the authorities. Activities have to be performed to understand the accuracy of the model, and this will be object also of future work.

\subsection{Considerations on probability of occurrence}

Probability of occurrence of an open burning may depend on many different key influence factors. Socio-cultural aspects of the inhabitants of the site can play an important role. Open burning is a multidimensional issue that incorporates social, political, institutional and economic aspects. Communities often turn to it because they feel they have no other options or consider it as the easiest way to manage their solid waste.

A model to evaluate the probability of occurrence of open burning completes the evaluation of the risk index linked to air contamination. It is composed by two elements: 1) Probability of Occurrence of open dumping; 2) Probability of Occurrence of open burning. The first element is largely affected by the lack of solid waste management policies and infrastructures, absence of realistic penalties or consistent enforcement, lack of social pressure to prevent littering, the inertia to change own habits, the awareness of the environmental impact of illegal open dump, culture of dirt [7]. The second element is less studied and is related to heterogenous factors: the need to destroy illegal waste, the need to remove the open waste since it is growing, or emanates bad smell. In the first case, the probability of burning is equal to 1 , in the second case it depends on turn on a set of other characteristics such as the accessibility of the site, the destination use of the surroundings in terms of the level of degradation of the site, historical data of the site. Its dependence on the time is controversial. On the one hand, the more time passes the more the amount of waste increases, the more the probability of open burning occurrence increases; on the other hand, the more time passes if the amount of waste does not increase, the more probably it will not be burned since it has been abandoned.

\begin{tabular}{|c|c|c|c|c|c|}
\hline & $\begin{array}{c}\text { Site } \\
\text { Recidivity }\end{array}$ & $\begin{array}{c}\text { Site } \\
\text { Accessibility }\end{array}$ & $\begin{array}{c}\text { Site Burning } \\
\text { Frequency }\end{array}$ & $\begin{array}{c}\text { Site Time } \\
\text { before } \\
\text { burning }\end{array}$ & $\begin{array}{c}\text { Site dirt } \\
\text { culture }\end{array}$ \\
\hline $\begin{array}{c}\text { Open dumping aims to } \\
\text { destroy illegal waste }\end{array}$ & High & High & High & Low & Low \\
\hline $\begin{array}{c}\text { P is medium } \\
\text { Open dumping in the site is } \\
\text { habitual }\end{array}$ & High & High & High & Medium & \\
\hline $\begin{array}{c}\text { Open dumping in the site is } \\
\text { casual }\end{array}$ & Low & Medium/Low & Low & High &
\end{tabular}

Fig. 5. Example of influence factor combination

The approach to model the probabilities can be incremental. It can start with a mapping of deep analysis of different social aspects and associating them with respect low-, medium- and high-income countries. Then, such factors can be combined in a qualitative model, Fig. 5. The next step is the definition of a numerical model. Behind the evaluation of each factor, the use of data analysis technique to correlate different elements and identify behavioural trends at varies geographical scale can overcome the point of non-linear behaviour, as future work addresses.

\section{Conclusion}

The presented work provides a preliminary study to design a complete model for open burning risk assessment. The use of a risk index to characterize the phenomenon may support the authorities in the definition of an optimal strategy to fight against it. Its evaluation enables an effective implementation of the mitigation plan in term of due time and resources. The paper discusses the possible usage in three different cases: during the occurrence of the open burning, when the illegal landfill has been detected, a-priori when assigned to areas that historically are prone to illegal dumping and burning. Thus, the presented model assures a complete coverage of the needs, and also a uniform approach to the different case studies. The proposed model for the evaluation of the impact merges the guidelines and the most recent literature studies on landfill compositions and on factor emission in order to automatically calculate the total impact factor. The layered approach allows to determine the impact also when data set is less accurate or not complete. In this case, the lack of accuracy is compensated by a set of conservative assumptions. The proposed approach can be easily integrated in any decision support system.

Further work is needed to refine the proposed model. The physical composition of the waste addressed by the model can be enlarged with the electronic components, considering additional related emission factors. The validation activities of the evaluation of the impact have to be performed on a greater set of data. In lack of data, a fleet of drones can be proposed to follow the cloud when the landfill is burning in order to acquire measures on the concentration of specific contaminants according to a grid of points in the area around the fire. This would enable a refinement of the theoretical model and also a better understanding of the accuracy that can be achieved and the errors implied by the done approximations.

The evaluation model of the probability of occurrence can complete the risk index. It is completely new and the proposed preliminary approach identifies influence factors that can determine at least qualitatively the level of probability. The use of Machine Learning techniques to determine the influence factors linked to behavioural patterns is a possible approach that can make the model scalable to different sites. Finally, the complete integration with some of the main existing transport models can represent the enabling key to make the approach easy to use from the most relevant stakeholder.

\section{Acknowledgment}

The proposed work has been developed within the Italian national funded project C4E Crowd for Environment from 2018 to 2021, aiming to develop a support decision system for the local authorities in the monitoring and removal of illegal waste. Founded by Italian Ministry of Research Grant $\mathrm{n}^{\circ}$ RNA-COR è 896199. 


\section{References}

1. Cogut, Alexander. "Open burning of waste: a global health disaster." R20 Regions of climate action (2016).

2. http://www.inemar.eu/xwiki/bin/view/InemarWiki/C onvegnoInemar

3. Risk Assessment Information System, https://rais.ornl.gov/cgibin/tools/TOX_search?select $=$ chemtox

4. https://www.isprambiente.gov.it/contentfiles/000020 00/2072-c1960-m3-u1-p3.pdf

5. https://www.isprambiente.gov.it/it/banchedati/banche-dati-folder/rifiuti

6. Daly, Aaron, and Paolo Zannetti. "Air pollution modeling-An overview." Ambient air pollution (2007): 15-28.

7. Emetere, M. E. (2019). An Overview of Theoretical Dynamics of Air Pollution. In Environmental Modeling Using Satellite Imaging and Dataset Reprocessing (pp. 39-69). Springer, Cham.

8. https://www.cmcc.it/models/cosmo-clm-climatelimited-area-modelling-community

9. WRAP, 2009, Summary Report - Material Bulk Densities, Report prepared by Resource Futures

10. Alabdraba, Waleed M. Sh, and Haneen AK AlQaraghully. "Composition of Domestic Solid Waste and The Determination of its Density \& Moisture Content: A case study for Tikrit city, Iraq." International Review of civil Engineering (I. RE. CE) Vol 4 (2013)

11. "Criteri metodologici per l'applicazione dell'analisi di rischio assoluta ai siti contaminati” APAT 2005 